\title{
Diagnóstico por imagem no trauma músculo-esquelético - princípios gerais
}

\author{
Diagnostic imaging in musculoskeletal trauma - \\ general principles
}

\author{
Marcelo Bordalo Rodrigues
}

Rodrigues MB. Diagnóstico por imagem no trauma músculo-esquelético - princípios gerais/ Diagnostic imaging in musculoskeletal trauma - general principles. Rev Med. (São Paulo). 2011 out.-dez.;90(4):185-94.

RESUMO: Os métodos de imagem são essenciais no diagnóstico de uma fratura óssea. A radiografia simples geralmente inicia a avaliação radiológica, fornecendo informações essenciais em relação as estruturas ósseas. Os demais métodos por imagem possuem um papel secundário, geralmente complementares ao RX, especialmente a RM e a TC. Estes métodos são utilizados em casos de ausência de anormalidade ao RX com exame clínico suspeito ou na necessidade de se fazer um estadiamento pré-cirúrgico mais detalhado, visando o planejamento cirúrgico.

DESCRITORES: Diagnóstico por imagem; Ferimentos e lesões/radiografia; Músculo esquelético/lesões; Músculo esquelético/radiografia.
ABSTRACT: Imaging methods are essential in the diagnosis of a bone fracture. Imaging evaluation starts with a simple x-ray, providing essential information regarding bony structures. Other imaging methods have a secondary role, complementary to the radiographs, especially MRI and CT. These methods may be used in cases of a normal $x$-ray with positive clinical examination or when a detailed presurgical evaluation is necessary.

KEYWORDS: Imaging diagnostic; Wounds and injuries/ radiography; Muscle, skeletal/injuries; Muscle, skeletal/ radiography.

\footnotetext{
Medico Coordenador do Serviço de Radiologia do Instituto de Ortopedia e Traumatologia (IOT) do HCFMSUP. Médico Responsável pela Radiologia Músculo-esquelética do Instituto de Radiologia (InRad) do HCFMUSP.

Endereço para correspondência: Marcelo B. Rodrigues. InRad-HCFMUSP. Av. Dr. Eneas de Carvalho Aguiar, $255-3^{\circ}$ andar. Cerqueira César. São Paulo, SP. CEP: 05403-001. E-mail: marcelo.bordalo @ hc.fm.usp.br
} 
Rodrigues MB. Diagnóstico por imagem no trauma músculo-esquelético.

\section{INTRODUÇÃO}

O trauma é a maior indicação de um estudo radiológico do esqueleto e é utilizado há cerca de 100 anos na medicina. Desde a descoberta do raio- $X$ pelo físico alemão Wilhelm Conrad Roentgen, sua aplicação na avaliação de fraturas e luxações recebeu imediata atenção' .

Entretanto, o raio-X, ou qualquer outro método por imagem, não é o instrumento mais importante na avaliação do trauma. A avaliação inicial inclui um exame físico cuidadoso e a determinação do mecanismo do trauma, sempre que possível. Os métodos por imagem não devem ser considerados como substitutos para a história e exame físico do paciente, pois diversas lesões ocorrem na ausência de achados radiológicos.

Após a avaliação inicial do trauma (ABC do trauma) e introdução das medidas terapêuticas correspondentes, fraturas e possíveis sítios de fraturas devem ser avaliados e, nos casos de necessidade, a conduta inicial deve ser a imobilização do segmento com suspeita ou com diagnóstico de fratura. As imobilizações auxiliam no manuseio do paciente e reduzem a morbidade no caso de feridos graves. Em seguida, apenas após estas medidas iniciais, é realizado o exame radiográfico.

É essencial a avaliação direcionada da radiografia, em correlação com a clínica. Diversas lesões são facilmente identificadas em uma radiografia, com diagnóstico prontamente estabelecido. Porém, existem situações em que o achado radiológico é sutil, podendo não ser visibilizado inicialmente. Nestes casos, é muito mais produtivo fazer uma avaliação radiográfica direcionada de uma determinada região levando em consideração o mecanismo de trauma e as circunstâncias em que ocorreu.

\section{TERMINOLOGIA DAS FRATURAS}

As fraturas são descritas e classificadas de acordo com sua localização, extensão, direção, posição e número de linhas de fraturas e fragmentos ósseos resultantes. Cada região do esqueleto possui suas próprias características de fratura e, conseqüentemente, sistemas de classificação próprios.

A fratura é inicialmente classificada em completa ou incompleta. A fratura completa apresenta uma solução de continuidade em todo o diâmetro ósseo e a fratura incompleta apresenta um segmento da cortical intacto.

A fratura completa é classificada em simples ou cominutiva (Figura 1). A fratura simples apresenta uma linha de fratura com dois fragmentos ósseos. A fratura cominuta (ou cominutiva) apresenta duas ou mais linhas de fratura, com, pelo menos, três fragmentos ósseos. O grau de cominução geralmente se relaciona diretamente com a magnitude da energia envolvida no trauma.

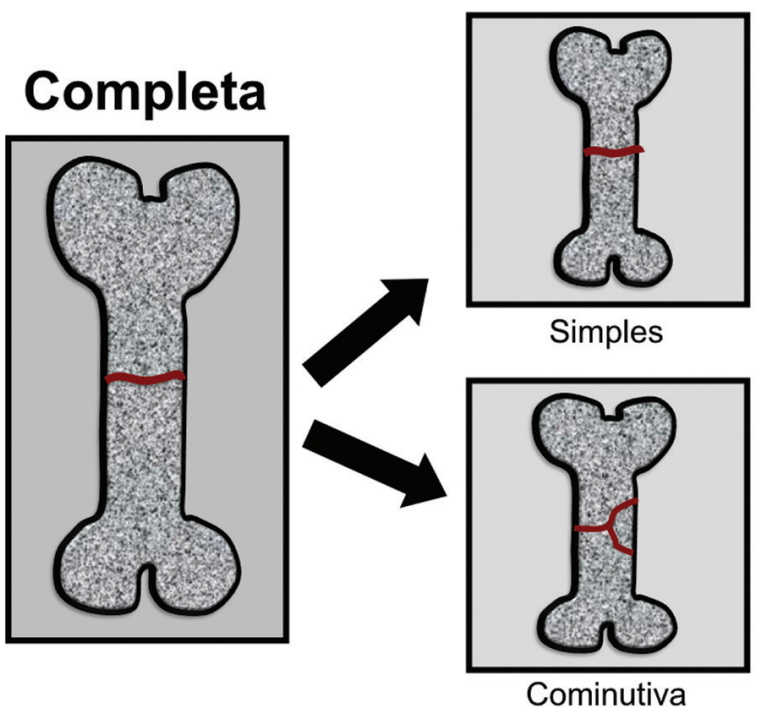

Figura 1. Fratura completa - Esquema. Esquema demonstrando a fratura completa (linha vermelha) acometendo todo o diâmetro ósseo. Esta fratura pode ser simples, se tiver apenas um traço de fratura com dois fragmentos ósseos ou cominutiva se tiver, pelo menos, duas linhas de fraturas com pelo menos, três fragmentos ósseos

A fratura que apresenta a pele adjacente intacta é denominada fechada. A fratura que apresenta lesão da pele associada com ou sem exposição óssea é denominada aberta.

A fratura decorrente da presença de uma lesão óssea focal (benigna ou maligna) é denominada patológica.

\section{Ossos longos}

Um osso longo é aquele em que o comprimento é maior que sua largura. Tipicamente possuem uma articulação em, pelo menos, uma extremidade. De acordo com a localização, a fratura pode se localizar na epífise, metáfise ou diáfise. Quando localizada na diáfise, deve-se descrever se ocorre no terço proximal, médio ou distal.

A direção da linha de fratura depende de sua relação com o eixo longo do osso. São classificadas em transversa, longitudinal, oblíqua ou espiral. Em casos específicos, especialmente na patela e na vértebra, a fratura pode ser classificada como horizontal ou vertical ${ }^{2}$.

A fratura Transversa ocorre perpendicular ao 
eixo longo de um osso e geralmente ocorrem por uma força direta aplicada ao osso. A longitudinal corre paralela ao eixo longo. A fratura oblíqua é muito comum, sendo aquela que corre ao longo do eixo longo do osso, em uma angulação de cerca de 30 a 60 graus (Figura 2). O mecanismo de lesão geralmente é uma força compressiva no eixo longo, combinada com um arqueamento do osso. A fratura Espiral circunda o osso, geralmente causada por forças torsionais. Suas extremidades em geral apresentam pontas afiadas (Figura 3).

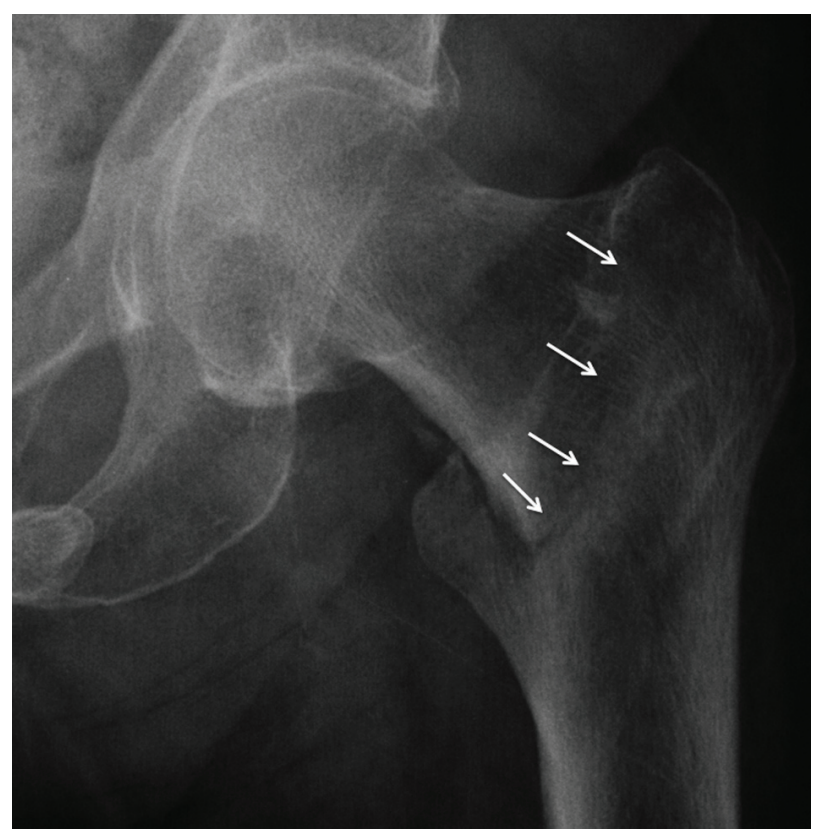

Figura 2. Fratura oblíqua - RX. Fratura linear oblíqua na linha intertrocantérica do fêmur proximal (setas). Esta fratura também é chamada de fratura transtrocanteriana

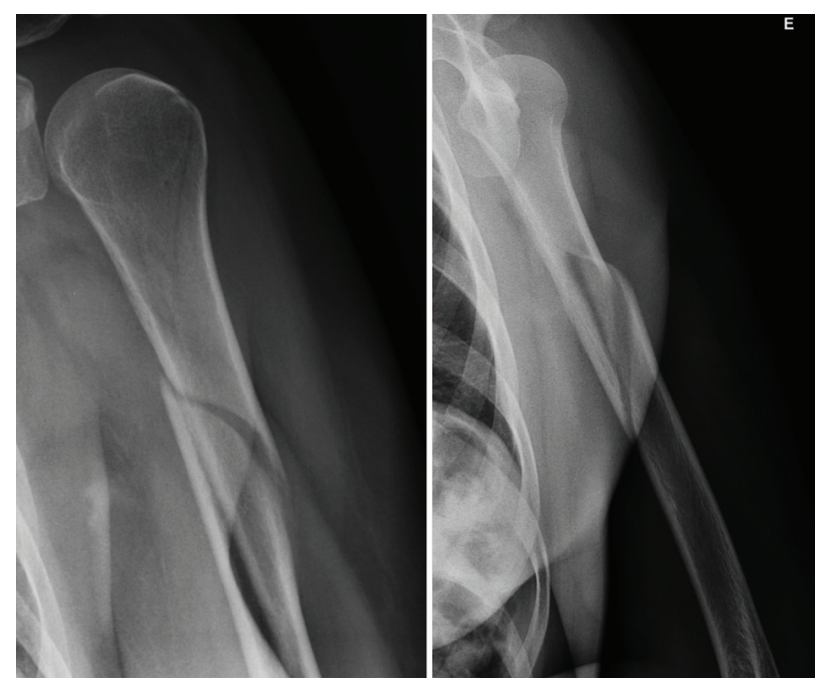

Figura 3. Fratura espiral - RX. Fratura espiral do úmero. Repare que o traço de fratura envolve o osso de forma circunferencial e as extremidades apresentam pontas afiadas
A relação entre os fragmentos ósseos também deve ser avaliada, especialmente o alinhamento entre os fragmentos em relação ao deslocamento, angulação, rotação, encurtamento ou afastamento. O deslocamento, angulação e rotação são descritos em relação ao fragmento distal (Figura 4).

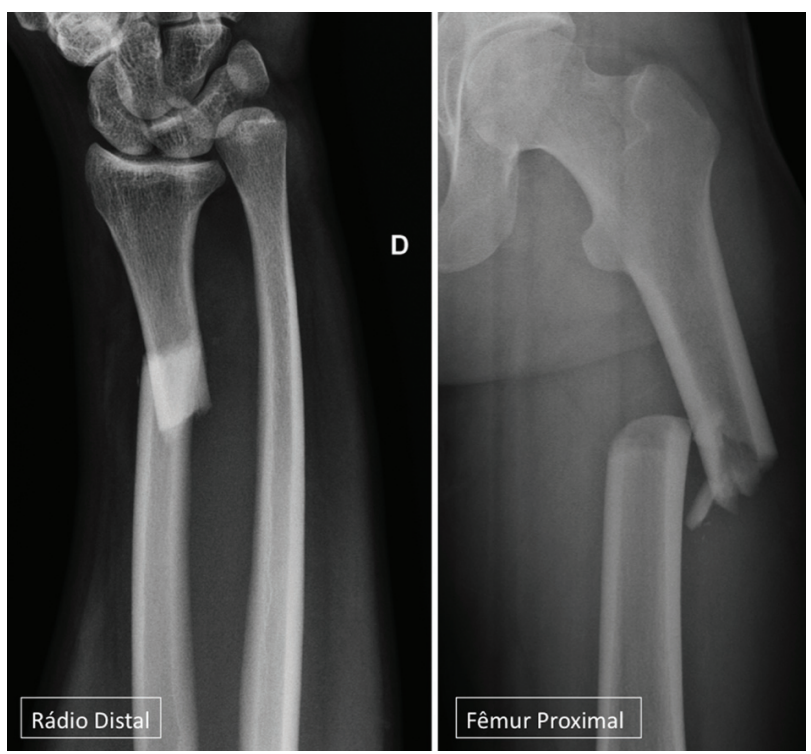

Figura 4. Desvios - RX. Fraturas lineares completas transversas do rádio distal e do fêmur proximal, determinando angulação medial e deslocamento medial, respectivamente. Esta terminologia é sempre em relação ao fragmento ósseo distal

A fratura avulsiva é aquela em que um fragmento ósseo é arrancado de uma proeminência óssea por uma força tensora na inserção de um ligamento ou tendão (Figura 5).

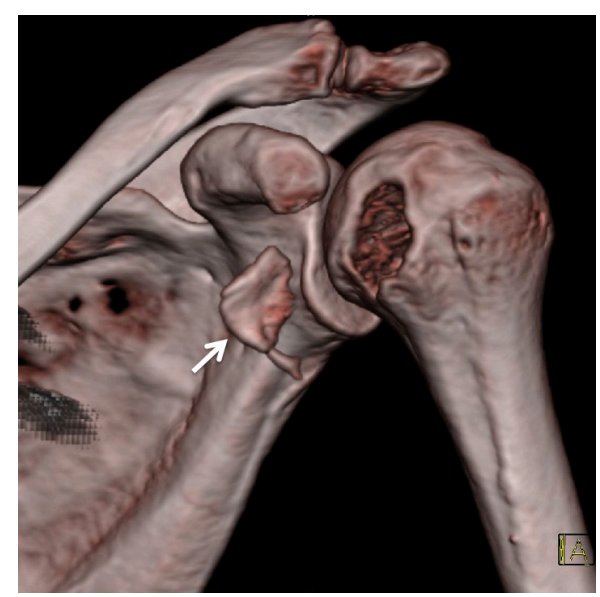

Figura 5. Fratura avulsiva - TC do ombro com reconstrução 3D de demonstra fratura avulsiva do tubérculo menor do úmero, com retração medial do fragmento ósseo avulsionado (seta) 
Rodrigues MB. Diagnóstico por imagem no trauma músculo-esquelético.

A fratura de um osso longo também pode estar relacionada a um deslocamento entre as superfícies articulares, sendo chamado de subluxação quando há uma perda parcial do contato e luxação quando há perda completa do contato entre as superfícies articulares. Neste caso, é chamada de fraturaluxação (Figura 6). Quando existe perda de contato entre uma sindesmose ou sínfise, o deslocamento é denominado de diástase (Figura 7).

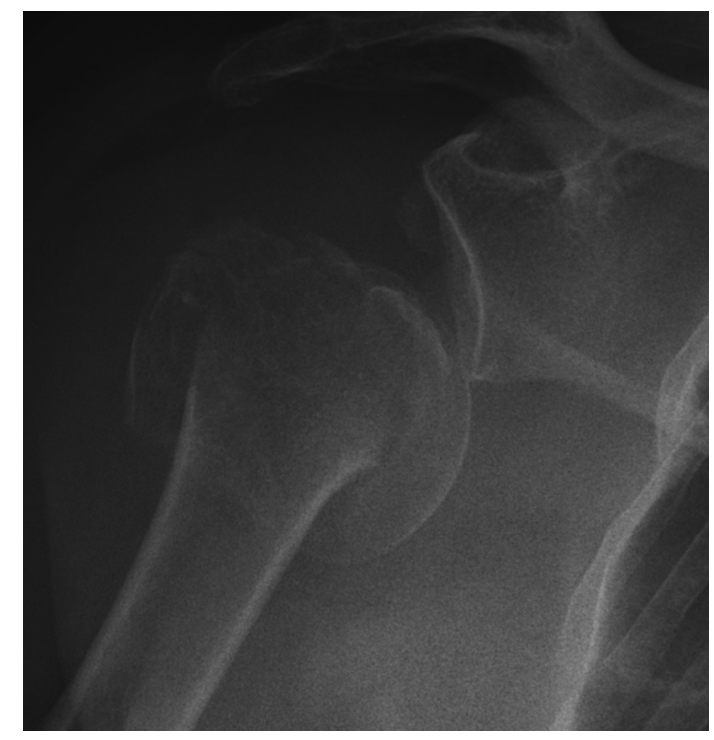

Figura 6. Fratura-luxação - RX. Fratura completa cominutiva do úmero proximal, associada a uma subluxação da cabeça umeral em relação à glenóide

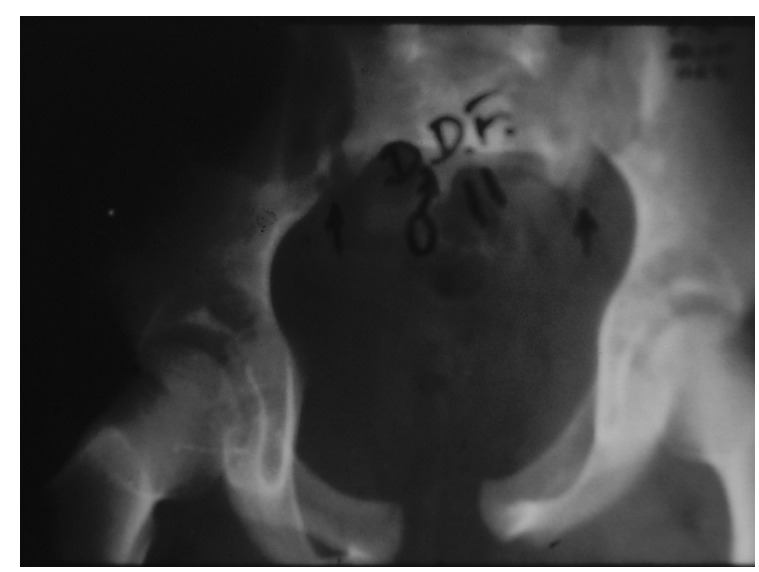

Figura 7. Diástase - RX. Diástase da sínfise púbica relacionada ao trauma

\section{Outros Ossos}

As fraturas dos ossos curtos (ossos do carpo e tarso), chatos (ilíaco, costela e calota craniana), irregulares (vértebras, púbis e ísquio), sesamóides e acessórios podem ser classificadas com a mesma terminologia utilizada para os ossos longos, sendo que em diversos casos, uma nova terminologia é aplicada. Por exemplo, uma fratura compressiva é aquela em que uma porção do osso é dirigida em direção a outro, como ocorre nas vértebras (Figura 8). A fratura-impactação é semelhante, porém descrita em ossos extra-vertebrais (Figura 9).

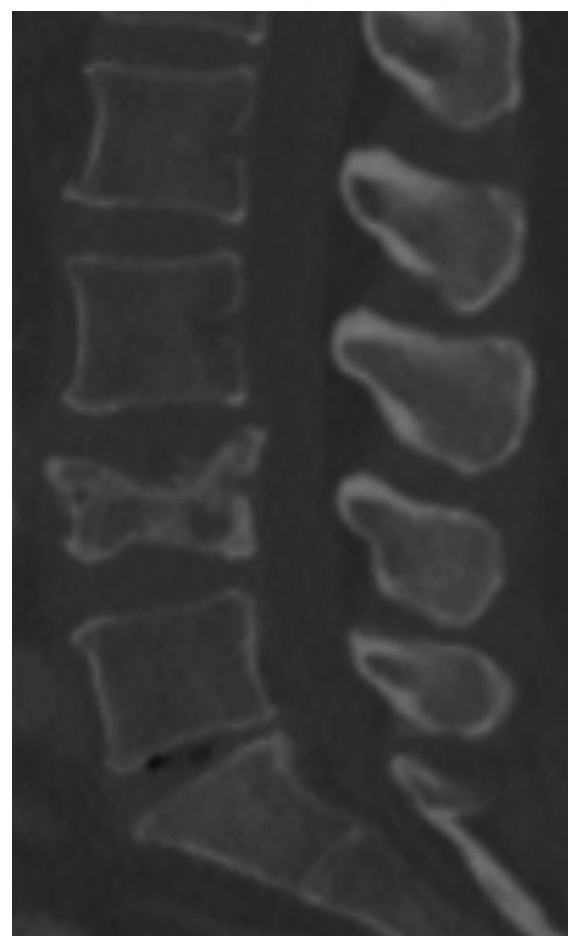

Figura 8. Fratura compressiva - TC. Fratura compressiva do corpo vertebral de L4, pós-traumática

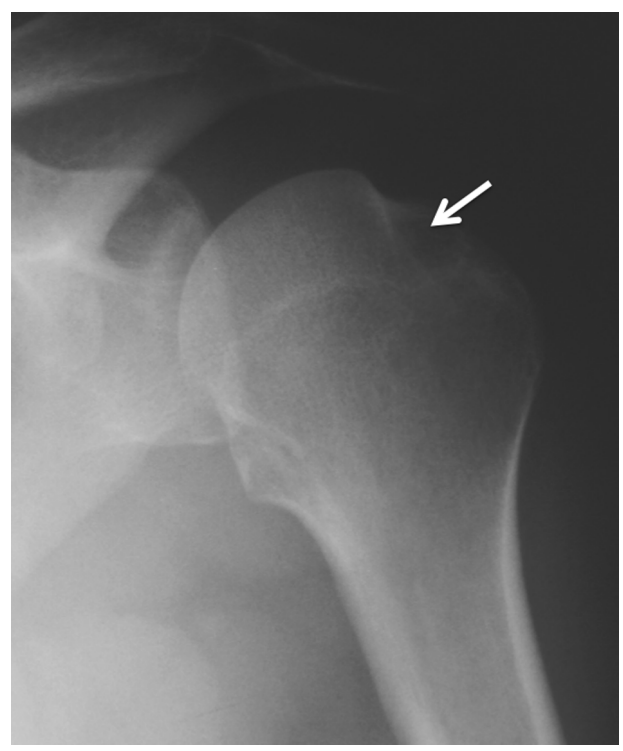

Figura 9. Fratura-impactação - RX. Fratura impactada da porção póstero-superior e lateral da cabeça umeral (seta), correspondendo a uma fratura de Hill Sachs, após uma luxação glenoumeral anterior 


\section{Fraturas específicas de crianças}

As diferenças nas propriedades biomecânicas do osso nas crianças em relação aos adultos propicia a formação de vários tipos de fraturas incompletas, tais como as fraturas em galho verde e tórus. A fratura em galho verde ocorre devido a forças angulares, provocando tensão do lado convexo do osso e compressão no lado côncavo. Isto leva a uma fratura incompleta na cortical convexa, estendendo-se por até a metade da circunferência do osso, semelhante a quebra de um galho verde com arqueamento do mesmo (Figura 10). Pode estar associada a um arqueamento do osso. A fratura em tórus é uma saliência na cortical óssea produzida por uma força compressiva, sendo frequentemente não diagnosticada (Figura 11).

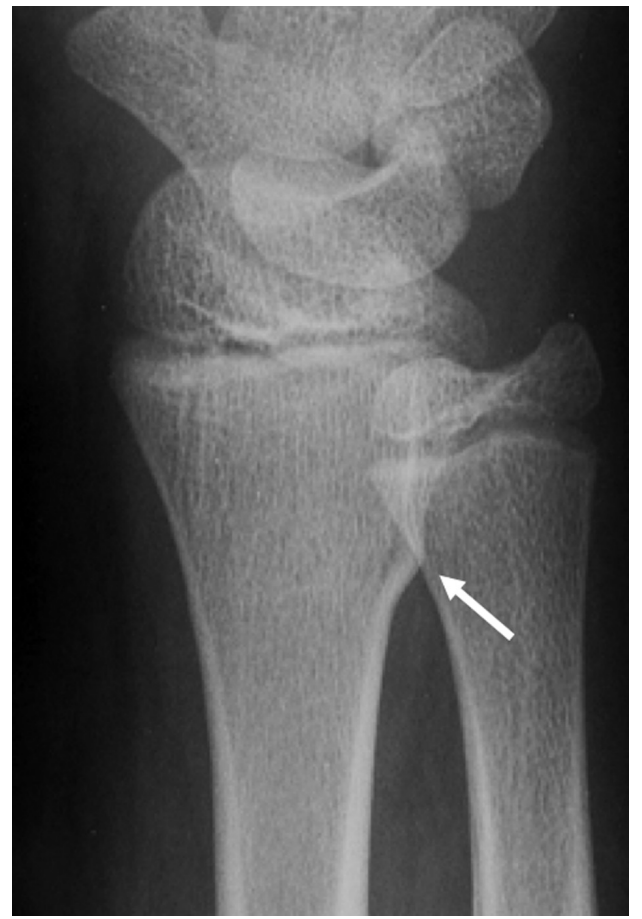

Figura 11. Fratura em tórus - RX. Pequena fratura cortical medial do rádio distal, determinando uma saliência cortical (seta)

As fraturas epifisárias são as mais comuns em crianças. Estas fraturas são descritas de acordo com a classificação de Salter-Harris ${ }^{3}$ (Figuras 12 a 17). A fratura tipo I é definida como uma separação metaepifisária, com a linha de fratura localizada na fise de crescimento. Ao raio- $X$, nota-se uma separação do centro de ossificação epifisário. A fratura tipo II é a mais comum, caracterizada por uma linha de fratura na fise de crescimento. estendendo-se para a metáfise óssea. A fratura tipo III é a fratura da fise estendendo-se para a epífise e superfície articular.

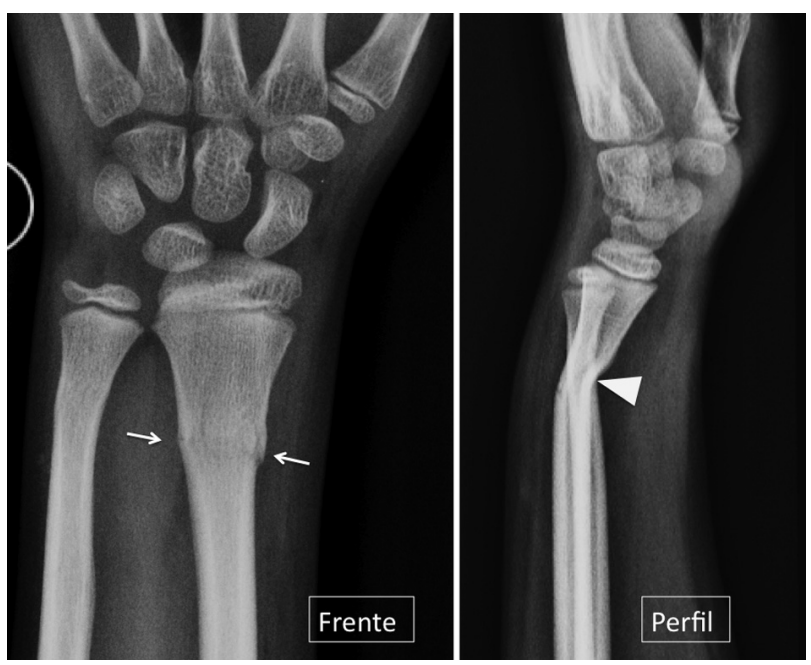

Figura 10. Fratura em galho verde - RX. Radiografias do punho (Frente e Perfil) em criança de 10 anos demonstram uma fratura em galho verde do rádio distal (setas), determinando uma angulação volar (cabeça de seta)

A fratura tipo IV ocorre frequentemente no côndilo lateral do úmero em crianças menores que 10 anos, apresentando uma orientação vertical, acometendo a metáfise, cartilagem de crescimento e epífise. A fratura tipo $V$ é rara, correspondendo a uma impactação da cartilagem de crescimento. Frequentemente, esta fratura não é vista ao raio- $X$, manifestando-se tardiamente como encurtamento ósseo e deformidades articulares.

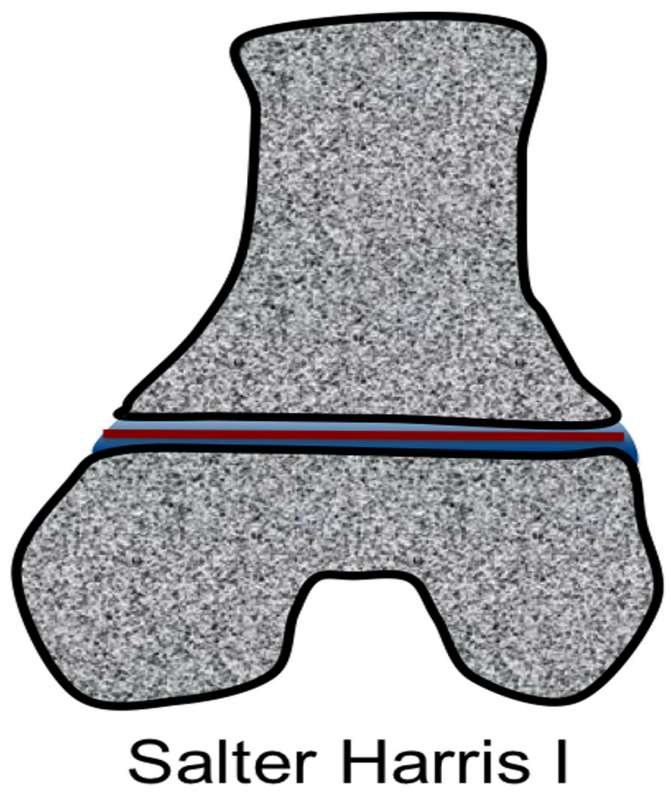

Figura 12. Salter Harris I - Esquema. Fratura linear na fise de crescimento (linha vermelha) sem impactação da mesma 


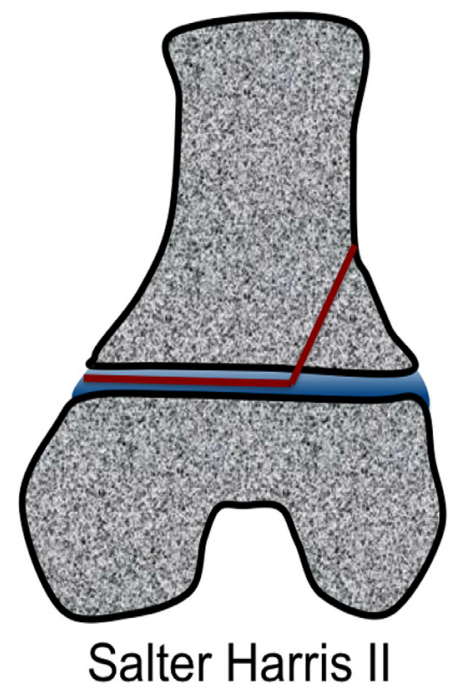

Figura 13. Salter Harris II - Esquema. Fratura linear na fise, estendendo-se para a metáfise

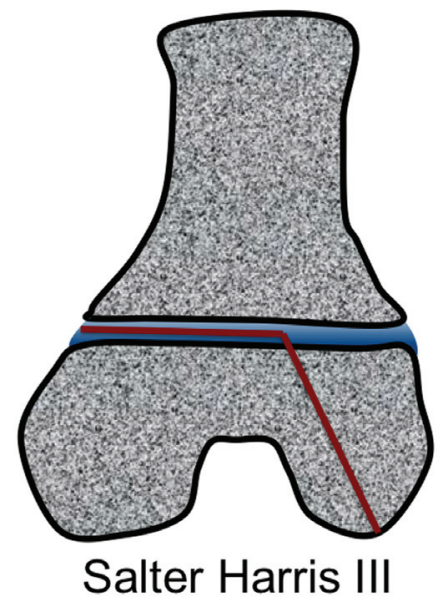

Figura 15. Salter Harris III - Esquema. Fratura linear na fise, estendendo-se para a epífise e superfície articular

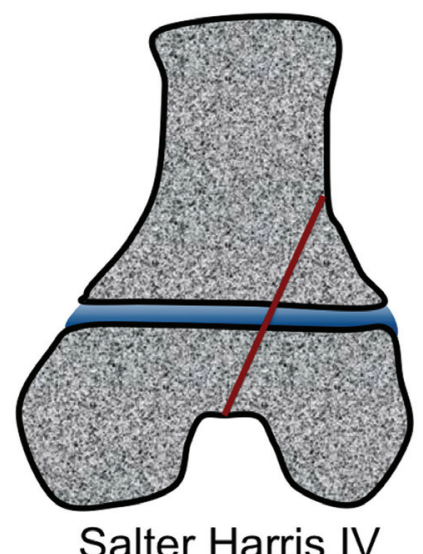

Figura 16. Salter Harris IV - Esquema. Fratura linear completa, estendendo-se desde a metáfise, passando pela fise de crescimento e estendendo-se até a epífise e a superfície articular

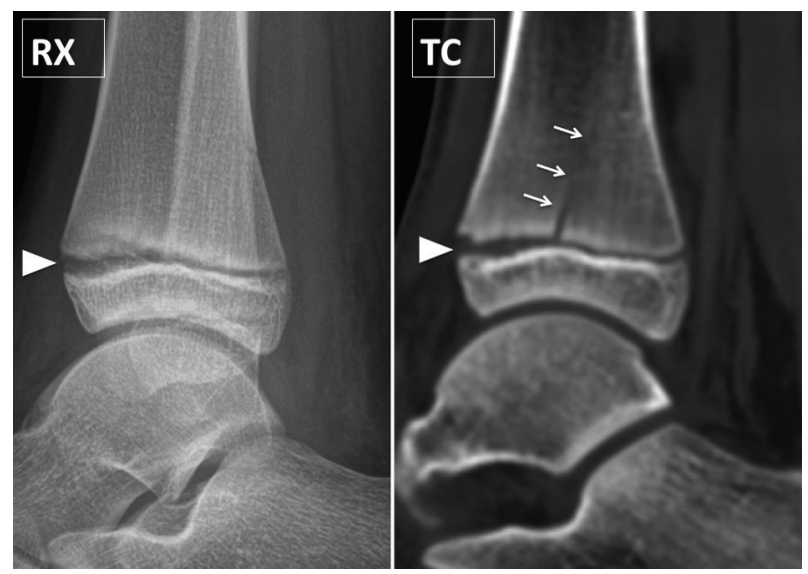

Figura 14. Salter Harris II - RX e TC. Radiografia em perfil do tornozelo demonstra alargamento anterior da fise de crescimento da tíbia (cabeça de seta), não se evidenciando traço de fratura óssea. A TC demonstrou que além do acometimento fisário, existia uma linha de fratura oblíqua que se estendia para a metáfise tibial (setas)

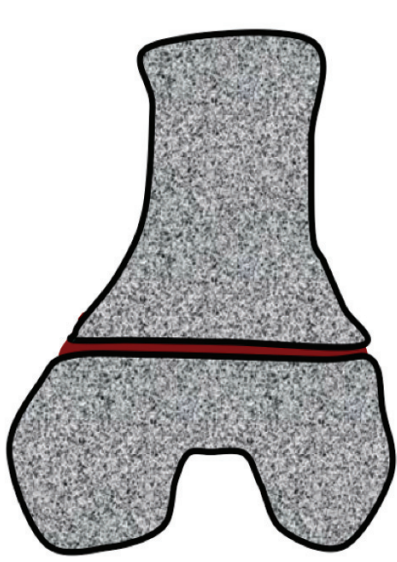

Salter Harris V

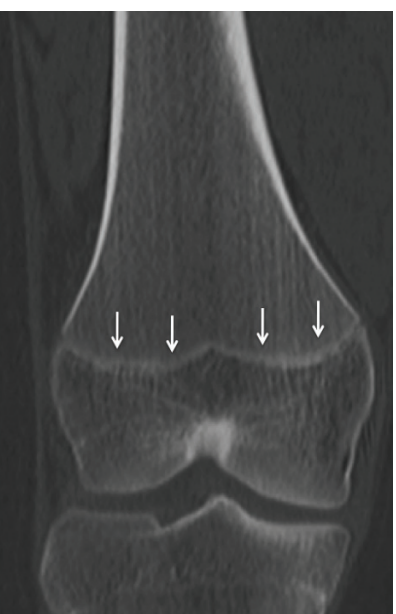

Figura 17. Salter Harris V - Esquema e TC. Fratura linear na fise apenas, com impactação da mesma

\section{RADIOLOGIA CONVENCIONAL}

É essencial a realização de radiografias de alta qualidade com o apropriado posicionamento do paciente. $O$ estudo radiográfico inicial deve incluir, pelo menos, dois planos distintos, obtidos em projeções de 90 graus de um em relação ao outro (frente e perfil). Dependendo da localização e morfologia da fratura, incidências adicionais podem ser necessárias.

A fratura aparece, em geral, como uma linha radiotransparente, podendo se manifestar como uma linha esclerótica nas fraturas compressivas.

A presença de alterações de partes moles ao raio-X podem sugerir a fratura nos casos mais sutis. Estas alterações incluem borramento e/ou deslocamento das linhas gordurosas, aumento de partes moles e derrame articular. No entanto, estes 
achados são inespecíficos, podendo estar presentes apenas relacionados ao trauma, sem fraturas.

Durante os últimos anos, houve o advento da imagem digital em radiologia. A aquisição ou conversão digital da imagem e sua distribuição eletrônica apresenta diversas vantagens sobre a radiografia em filme, tais como:

$>$ possibilidade de distribuição da imagem para diversos usuários em locais distintos e com rapidez; imagens;

$>$ fácil localização e armazenamento das

$>$ menor espaço físico necessário para armazenamento das imagens;

$>$ possibilidade de aplicar técnicas de processamento de imagens.

Para a avaliação das fraturas, as radiografias digitais necessitam de uma alta resolução espacial para avaliar pequenos detalhes ósseos e a capacidade de avaliar tecidos com valores de atenuação muito diferentes (osso e partes moles). Os novos aparelhos de conversão digital (CR) ou aquisição digital (DR) produzem imagens como uma resolução igual ou superior aquelas obtidas de forma analógica, através de filmes radiográficos ${ }^{4,5}$.

\section{TOMOGRAFIA COMPUTADORIZADA (TC)}

A TC apresenta grandes vantagens em relação às radiografias convencionais, pois elimina a superposição de estruturas nas imagens, tendo utilidade na avaliação de órgãos com uma anatomia complexa, difíceis de serem avaliadas pelas radiografias simples.

Com o desenvolvimento tecnológico e o aparecimento dos novos aparelhos com multidetectores, imagens multiplanares e tridimensionais de alta resolução passaram a ser obtidas (Figura 18). Além de permitir um diagnóstico mais preciso, tais imagens também podem ajudar 0 cirurgião ortopédico a planejar o tratamento.

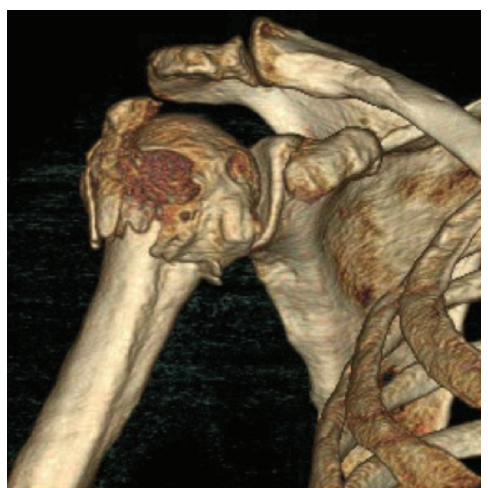

Figura 18. Fratura de úmero proximal - TC do ombro com reconstrução 3D demonstra fratura cominutiva do úmero com fragmentos deslocados
A TC multidetectores é hoje o método de escolha para o estadiamento das fraturas do esqueleto axial ${ }^{6}$. A capacidade de obtenção de imagens multiplanares permite a localização exata das fraturas, a pesquisa de fragmentos intraarticulares, luxações e uma mensuração precisa de desvios.

\section{RESSONÂNCIA MAGNÉTICA (RM)}

A RM é o método por imagem com melhor contraste entre osso, medula óssea, músculos, liquido, gordura e vasos. A RM é capaz de detectar a fratura, porém apresenta papel limitado em seu diagnóstico e estadiamento, pois existem métodos mais simples e com custo menor para este fim. No caso do estadiamento das fraturas, o RX e a TC são, na maioria das vezes, superiores a RM.

O papel da RM é crucial no diagnóstico das fraturas ocultas. Estas fraturas não são visíveis ao $\mathrm{RX} / \mathrm{TC}$. Diante disto, devido ao quadro clínico muito evidente para fratura ou suspeita de lesão em partes moles, uma RM é indicada e a fratura pode ser detectada, caracterizando a fratura oculta (Figura 19).

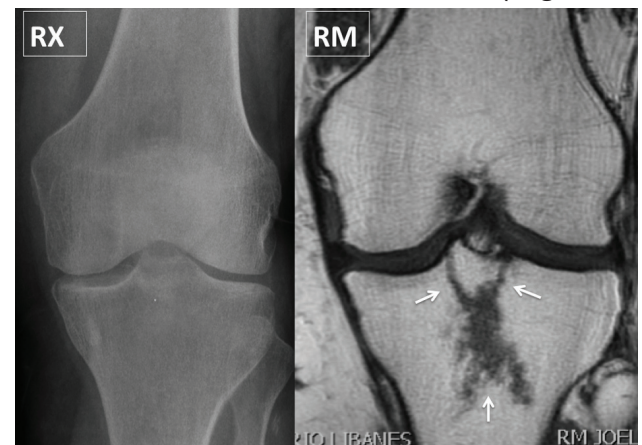

Figura 19. Fratura oculta - RX e RM. Radiografia do joelho 1 dia após trauma motociclístico não evidencia fraturas. Devido ao quadro clínico muito suspeito para fratura, foi realizada RM no mesmo dia, evidenciando fratura cominutiva do platô tibial, sem desalinhamentos (setas)

A RM também pode ser indicada nos casos de suspeita de fraturas da fise de crescimento nas crianças e lesões osteocondrais nos adultos, pois é o melhor método para avaliação da cartilagem (Figura 20).

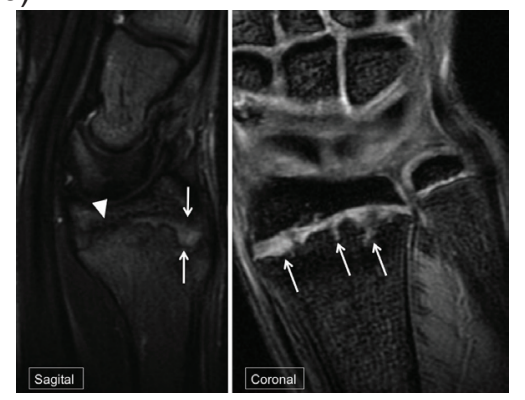

Figura 20. Lesão da fise de crescimento - RM. Imagens sagital e coronal de RM do punho demonstram alargamento e hipersinal da fise de crescimento, indicando lesão (setas). Notar o aspecto normal da fise na imagem sagital (cabeça de seta) 
Rodrigues MB. Diagnóstico por imagem no trauma músculo-esquelético.

Análise critica do diagnóstico por imagem das fraturas

Os métodos por imagem que podem ser utilizados na avaliação de um trauma agudo são o raio-X, tomografia computadorizada e a ressonância magnética.

A maioria das fraturas são identificadas nas radiografias simples, sendo necessário, por vezes, uma "segunda olhada" após o exame clínico do paciente. Quando a radiografia tecnicamente aceitável é normal, porém ainda existe a suspeita clínica de fratura, os métodos por imagem seccionais são indicados quando a decisão da conduta é critica. Em algumas situações, uma radiografia evolutiva de seguimento pode ser mais apropriada que métodos por imagem adicionais, especialmente quando a conduta seria imobilização simples de qualquer maneira. Após uma ou duas semanas, a presença de consolidação da fratura torna fraturas não deslocadas visíveis ao $\mathrm{RX}$, devido a um aumento da reabsorção óssea junto ao sitio da fratura.

Em geral, a porcentagem de resultados positivos na radiografia simples de extremidades é de $20 \%{ }^{7}$. Um outro estudo demonstrou que cerca de $70 \%$ das radiografias ósseas obtidas no prontosocorro após um trauma eram normais ${ }^{8}$. Os exames com maior proporção de normalidade eram a coluna cervical ( $89 \%$ eram normais), coluna torácica (87\%) e joelho (86\%). A proporção de exames com achados alterados pode aumentar se o critério clínico para indicar uma radiografia for estreitado, reduzindo a porcentagem de pacientes indicados para realizar um $\mathrm{RX}$. Existem critérios diagnósticos que podem ser utilizados para indicar racionalmente uma radiografia, baseados nos achados clínicos e em critérios funcionais. Como exemplo, temos as regras de Ottawa para o pé, tornozelo e joelho e de Pittsburgh para o joelho ${ }^{9-11}$. Também existem critérios diagnósticos para diversas situações clínicas, desenvolvidos pelo Colégio Americano de Radiologia (consultar www.acr.org).

A TC tem maior importância na avaliação do trauma do esqueleto axial (crânio, face, coluna e bacia), tendo papel limitado na avaliação inicial do trauma no esqueleto apendicular. No esqueleto apendicular, uma fratura observada na TC geralmente é visível no $\mathrm{RX}$, porém com maiores detalhes na TC, também podendo ser utilizada no planejamento pré-operatório, devido a sua capacidade multiplanar. No paciente politraumatizado grave, a TC pode ser utilizada na avaliação do crânio, coluna total, tórax, abdome total e pelve devido a sua rapidez e menor necessidade de manipulação do paciente, em relação ao RX. Porém esta indicação ainda está limitada aos serviços que possuem um aparelho de TC com multidetectores, devido a sua rapidez e capacidade diagnóstica.

A RM é capaz de detectar uma fratura, porém tem papel limitado no diagnóstico e na conduta, pois existem métodos mais simples e com menor custo para este fim. A RM pode ser indicada quando o $\mathrm{RX}$ for normal, porém exista uma suspeita clínica de fratura (fraturas ocultas). Outra indicação é na pesquisa de fraturas osteocondrais, sendo possível, inclusive, avaliar o deslocamento deste fragmento. Também é utilizada para avaliar a necrose póstraumática de fragmentos ósseos, especialmente na cabeça femoral, dômus talar e escafóide proximal, sendo o método mais sensível para detectar estágios mais precoces de osteonecrose (Figura 21). O comprometimento da cartilagem de crescimento (fise) também é bem avaliado pela RM. Outras indicações são: avaliação de uma fratura patológica, com intuito de se verificar um tumor associado a fratura e também na avaliação de achados extra-ósseos associados ao trauma (partes moles - cartilagem, ligamentos, labruns, meniscos, etc).
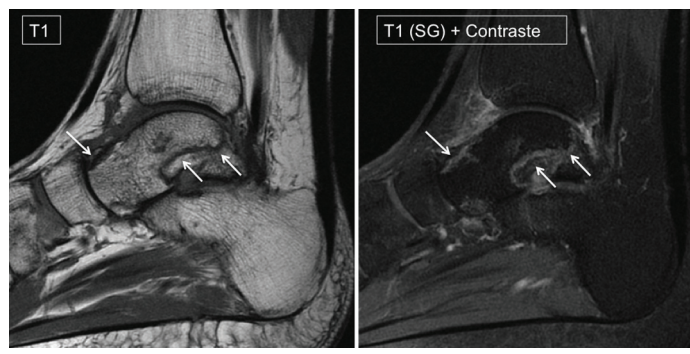

Figura 21. Osteonecrose - RM. Imagens sagitais de RM do tornozelo ponderadas em T1 e em T1 com saturação de gordura (SG) e contraste endovenoso. Este paciente sofreu uma luxação traumática do talus e 5 meses após a redução cruenta, nota-se o aparecimento de osteonecrose do talus, caracterizado pela presença de uma lesão geográfica sem realce pelo meio de contraste (setas)

\section{Consolidação das Fraturas}

O mecanismo de consolidação da fratura inicia-se imediatamente após o evento, com formação de um hematoma e coágulos que realizam a hemostasia no sitio da fratura ${ }^{12}$. Em cerca de 1-2 semanas, há formação de fibroblastos e tecido de granulação, que removem o hematoma. Nesta fase, também se inicia a ação de osteoclastos, removendo osso morto das superfícies de aposição da fratura. Ao mesmo tempo, também se inicia a ação dos condroblastos e osteoblastos com produção das matrizes óssea e cartilaginosa ${ }^{13,14}$. Este processo inicia-se na periferia da fratura, formando uma "ponte" óssea ou fratura e dura de 4 a 16 semanas para se formar.

O achado mais precoce do reparo ósseo 
aparece em 10 a 14 dias após o trauma, constituído pela radioluscência das superfícies ósseas junto ao foco de fratura, com borramento das margens de aposição. Em seguida, aparece o calo calcificado no foco de fratura, apresentando aspecto amorfo na periferia da fratura ${ }^{2}$. O calo intramedular não é visibilizado nesta fase. Com o tempo, o calo vai aumentando sua densidade e a medida em que há a fusão periférica, inicia-se a formação do calo central ou intramedular.

A evidência radiográfica de consolidação da fratura constitui a presença de uma "ponte" óssea externa, unindo os fragmentos ósseos (Figura 22). Pode ser necessária a obtenção de uma incidência oblíqua em adição as outras duas para visibilizar a consolidação. Caso ainda haja dúvida, pode se lançar mão de uma TC com reformatações multiplanares. Deve-se lembrar, no entanto, que a consolidação óssea é melhor determinada pelos exames clínico e físico, sendo a radiografia um exame complementar.

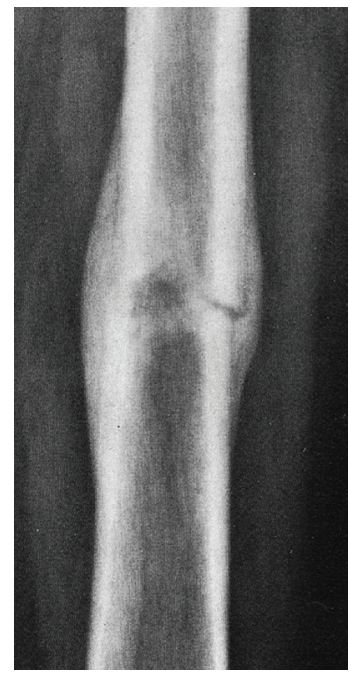

Figura 22. Consolidação de fratura $-R X$. Presença de calo ósseo formando uma "ponte" entre os fragmentos ósseos, caracterizando uma consolidação adequada

O tempo de consolidação óssea depende da idade do paciente e do osso fraturado. Como exemplos, em um adulto, a consolidação de ossos curtos, como os metacarpos e a clavícula, ocorre em 3-4 semanas; a diáfise umeral em 6-8 semanas; a diáfise tibial em 10-12 semanas e a diáfise femoral em 12-14 semanas. Nas crianças jovens, a consolidação de uma fratura do fêmur ocorre em cerca de 4 semanas, sendo que os outros ossos se unem em tempos menores.

\section{Problemas na Consolidação das Fraturas}

A consolidação viciosa é a união defeituosa entre os fragmentos ósseos, geralmente associada a importantes deformidades angulares ou rotatórias (Figura 23). Em adolescentes e adultos, geralmente é necessária uma correção cirúrgica, enquanto em crianças, existe a possibilidade de correção com o próprio crescimento do osso.

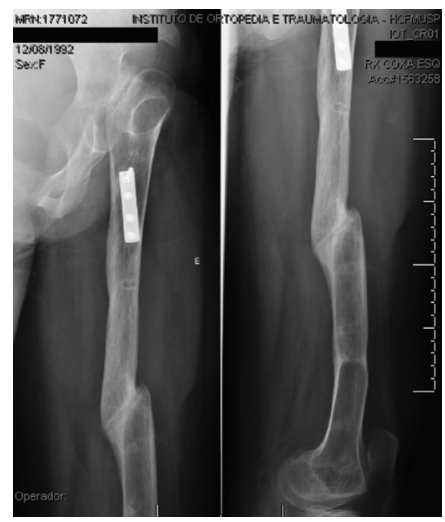

Figura 23. Consolidação viciosa - RX. Fratura consolidada do fêmur, porém com desalinhamento e angulação entre os fragmentos ósseos

A falha na consolidação depende de fatores técnicos e/ou biológicos. Os fatores técnicos são responsáveis por cerca de $80 \%$ dos casos de não união e incluem uma aposição inadequada entre os fragmentos ósseos e excesso de movimentação entre os fragmentos. Os fatores biológicos são responsáveis por cerca de $20 \%$ dos casos. Esta falha na consolidação pode ser um retardo ou uma ausência de consolidação. O retardo na consolidação é caracterizado pela lentificação da união óssea o que não significa que haverá a consolidação e, sim, que a mesma ocorrerá em um ritmo mais lento ${ }^{13}$. A não união significa uma falha completa no processo de consolidação, sendo mais freqüente em adultos. Existem dois tipos de não-união, a hipertrófica e a atrófica. A hipertrófica ocorre quando existe esclerose nas extremidades dos fragmentos ósseos e a atrófica quando existe mínima esclerose (Figuras 24 e 25). Entre os fragmentos ósseos não fundidos, forma-se um tecido fibroso e uma saculação com liquido, dando o aspecto de uma articulação. Por este motivo, a não união também é chamada de pseudoartrose (Figura 26).

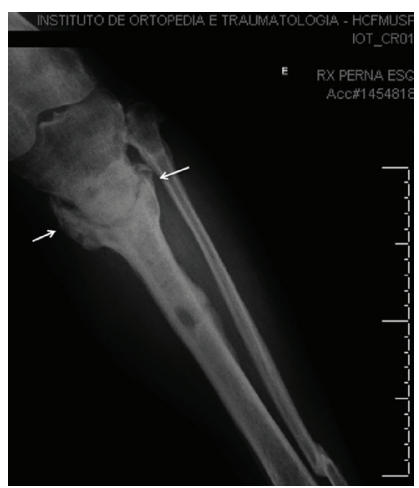

Figura 24. Ausência de consolidaçãodotipohipertrófica - RX. Pseudoartrose na tíbia proximal, com fragmentos ósseos hipertróficos e com esclerose junto ao foco de fratura 
Rodrigues MB. Diagnóstico por imagem no trauma músculo-esquelético.

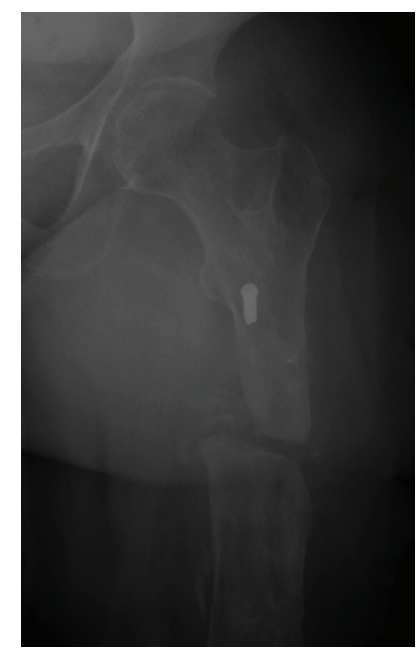

Figura 25. Ausência de consolidação do tipo atrófica $R X$. Pseudoartrose no fêmur proximal com rarefação junto ao foco de fratura

\section{REFERÊNCIAS}

1 Peltier LF. The impact of Rontgen's discovery upon the treatment of fractures. Surgery. 1953;33:579-86.

2 Rogers L. Radiology of skeletal trauma. 3rd ed. Philadelphia: Churchill Livingstone; 2002.

3 Salter RB. Injuries of the epiphyseal plate. Instr Course Lect. 1992;41:351-9.

4 O'Connor PJ, et al. Reporting requirements for skeletal digital radiography: comparison of soft-copy and hardcopy presentation. Radiology. 1998;207:249-54.

5 Richmond BJ, et al. Diagnostic efficacy of digitized images vs plain films: a study of the joints of the fingers. AJR Am J Roentgenol. 1992;158:437-41.

6 Gilula LA, Murphy WA, Tailor CC, Patel RB. Computed tomography of the osseous pelvis. Radiology. 1979;132:107-14.

7 Brand DA, et al. A protocol for selecting patients with injured extremities who need x-rays. N Engl J Med. 1982;306:333-9.

8 Lee SI, Chew FS. 1998 ARRS Executive Council Award. Radiology in the Emergency Department:

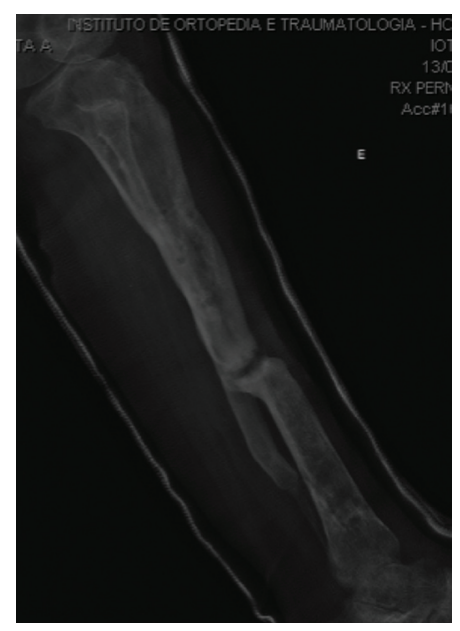

Figura 26. Pseudoartrose-RX. Pseudoartrose hipertrófica no terço médio da tíbia

technique for quantitative description of use and results. American Roentgen Ray Society. AJR Am J Roentgenol. 1998;171:559-64.

9 Stiell IG, et al. Decision rules for the use of radiography in acute ankle injuries. Refinement and prospective validation. JAMA. 1993;269:1127-32.

10 Stiell IG, et al. A study to develop clinical decision rules for the use of radiography in acute ankle injuries. Ann Emerg Med. 1992;21:384-90.

11 Bauer SJ, Hollander JE, Fuchs SH, Thode HC Jr. A clinical decision rule in the evaluation of acute knee injuries. J Emerg Med.1995;13:611-5.

12 Cruess RL, Dumont J. Fracture healing. Can J Surg. 1975;18:403-13.

13 Frost HM. The biology of fracture healing. An overview for clinicians. Part I. Clin Orthop Relat Res. 1989:28393.

14 Frost HM. The biology of fracture healing. An overview for clinicians. Part II. Clin Orthop Relat Res. 1989:294309. 